\title{
Study on the Criminal Regulation System of Freedom of Speech under the New Media Environment
}

\author{
Huang Nini \\ (Wuhan Donghu University, Wuhan 430212 )
}

Keywords: New media; Anomie speech; Criminal law rules; Freedom of speech

\begin{abstract}
In recent years, with the development of new media, the micro-blog, WeChat, QQ, Q\&A community and other pan-network products have become the main way for network users to exchange information. These new media platforms are convenient for users, but followed with obvious information ecological problems, such as network infringement, network mob breeding and network environmental pollution. Freedom of speech is the freedom of the citizens granted by the Constitution, but it does not mean that it is not bound by the law. When the words and deeds destroy certain legal interests, it will constitute an illegal act. For those anomie speeches that have serious social harm, the criminal law is needed to regulate them. This paper takes the anomie speech in the We Media environment as the research object, summarizes the relevant crimes in the criminal law, analyzes the existing application difficulties combining the cases, and finally proposes the advice about perfecting the criminal law regulation on the network anomie speech in China through the analysis and reference of relevant foreign laws.
\end{abstract}

\section{Introduction}

In the new media era, not all communication is positive and healthy, and sometimes it is full of risks, harms and distrust, and rumors are the most typical representatives. In the era of complex and ever-changing new media, along with the spread of informatization digitalization, rumors are also born with the network. Everyone is a communicator, and each one can be the maker, communicator and victim of rumors. In today's social and information environment, online rumors still spread like viruses in all corners of society, and even in full swing. Therefore, it is necessary to find a strong balance between freedom of speech and online rumor regulation. It is an effective way to deal with the governance of online rumors at this stage, mainly from improving the ability of government information disclosure, encouraging freedom of speech and establishing special Internet regulations to jointly shape healthy, superior internet public opinion ecological environment. In this context, the paper discusses the criminal law regulation for the network anomie speech, and the criminal law should follow the principle of necessity, clarity and democracy. In particular, relevant provisions should be added through the amendment of the Criminal Law, and relevant judicial interpretations should be introduced. Criminal justice rules should be applied strictly to improve.

\section{Performance of freedom of speech under the new media environment}

Immediacy of the release of speech $\square \square$

The immediacy of the release of speech mainly means that citizens can use the new media technology to upload information to the Internet in a matter of seconds through a single computer or smart phone, and the information receiver can receive the information with several seconds after it's sent. In short, citizens can quickly spread what they see and hear through new media technologies. Taking the news media as an example, the traditional media news production process is complex and requires special professional apparatus, equipment and professional institutions to operate (the traditional Chinese media must be reviewed by relevant departments before they can be released).

The equality of the speech subject

The equality of the speech subject means that in the new media environment, everyone can fully express their opinions and is free from the political status, economic strength, cultural differences and other factors in real life, and get rid of the influence of other factors, such as geography, gender, 
ethnicity and occupation. One of the main reasons why citizens' right to freedom of speech can be fully utilized in online media is the anonymity of online speech.

The interactivity of speech communication

The interactivity of speech communication refers to the reading feedback as the starting point, forming a mutual feedback, organic, spontaneous virtuous circle. In the traditional media era, due to the limitations of technology and the unequal status between the media and the audience, the mode of communication is often top-down one-way transmission, the communicator and the audience cannot communicate interactively, and the readers lack of feedback channels. The feedback will be neglected even if it is formed. Secondly, the advantages of large-scale replication of traditional media may lead to rapid expansion of errors and high cost of correction.

\section{The harms of We Media speech anomie}

Anomie is the weakening or even breaking of social norm system that reflects the community of beliefs and feelings. This is a kind of "freedom" that tries to get rid of social control in disastrous way. In this freedom, in the face of life, people have no way to get a clear direction and meaning. The anomie of online speech is a kind of social anomie. It is an abnormal state due to the disorder of online speech. In the network environment, people lack of behavioral norms that can be observed together. It is a state of tension or break with the cultural goals and realistic goals advocated by the general in legal institutionalized method.

In the entire network society, the speech activities of the netizens have been diversified and personalized, but the coexistence of good and bad, and some speeches have obviously deviated from the social behavior norms, and are also judged as the emotions, thoughts, and actions that violate their values or social norms by members of all societies. "Lost" has the meaning of loss, change, and failure; while "regulation" refers to the values, behavioral norms, normal order, and mainstream consciousness that people should have in the real society and the network society. At the behavioral level, this kind of anomie embodies that a small number of netizens no longer follow this value, norms of behavior, normal order, and mainstream consciousness, and then deliberately violate social morality and behavioral norms for their own interests, even touch the bottom line of the law and regulations, which in turn has a negative impact on the healthy operation of the network society and ecological clarity.

Since the speech anomie is concealed in the We Media environment, and it is often spoken anonymously. The speech of anonymity has also led to fission and explosion of the phenomenon of network speech anomie being prominent. Some people use the hidden features of the network society to spread bad data information and issue rumors casually, attack on individual citizens and even state institutions.

\section{Complete thinking on the criminal regulations for anomie speech in the We Media environment}

For the perfection of the criminal regulation of anomie speech in the We Media environment, it should be carried out at both the legislative and judicial levels. Firstly, the basic principles to be followed in the legislative improvement should be established and legislative proposals should be proposed. At the same time, the specific application of criminal legislation in judicial practice must be paid special attention to. If necessary, the corresponding judicial interpretation of the criminal law should be issued, and the specific application rules in the judicial should be clarified.

1. The principle of necessity

It is necessary to make a standard judgment on whether the network anomie is a constitutional expression of freedom of speech. Although there are inadequacies in the network speech anomie, as a carrier of expression or meaning, as long as it is still in the criminal range of freedom of speech guaranteed by the Constitution at the normative value level, it does not have the necessary of criminal law intervention and regulation.

2. The principle of democracy. 
The essence of socialism is that the people are the masters of the country, and the legislation can only truly realize the value of justice if it reflects the will of people. The only way to understand the needs and wishes of citizens is to depend on citizens themselves. It may lead to conflicts between the two parties by simply relying on the legislature departments which lack of the necessary grassroots feelings and practical effects, and the social effects are not satisfactory. China's "Legislation Law" stipulates that legislation should reflect the will of the people, encourages and guarantees citizens to participate in legislative activities through various means, in order to guarantee the free expression of citizens' demands and the smooth realization of legitimate interests.

3. The principle of clarity.

The characteristics of legal text require clarity, and its content should be understood and foreseen generally. By reading the law, citizens can discern whether their actions constitute a crime, and they can also anticipate the criminal punishments they will suffer after breaking the law, in order to regulate their own words and deeds and build a good social order. At the same time, clarity is also a guarantee of civil rights. If the provisions of the criminal law are too general and vague, it will make the citizens overburdened. If the network speech too much easy to violate the criminal law, it is also the destruction of the citizens' freedom of speech. Anomie speech under the We Media environment will not only infringe on individual rights, but more importantly, it will have a serious impact on social public order. According to the views of relevant scholars, the meaning of social public order can be summarized as a structured and normal social operation state including social production, operation, management, and life, which is established and maintained by relying on the legal system, social public moral regulation, and customs.

\section{Conclusion}

Freedom of speech is the basic political right of citizens under the constitutional guarantee and reflects the degree of social democracy. The emergence of the Internet platforms has brought prosperity for the We Media, and ordinary people can express their demands more freely in virtue of it. The dissemination and communication of information through network speech has promoted the development of the times and social communication. The current network has also become an important position in China's anti-corruption work and has made positive contributions to the socialist rule of law. This paper puts forward some suggestions for perfecting the criminal legislation of speech anomie in the We Media environment. We hope that make reasonable rules through the dual path of criminal law amendment and legal interpretation. At the same time, it is suggested that it should be targeted in judicial use and for the subjectively unintentional personal speech, the application of criminal law should be avoided. And for group crimes and public knowledge, it's necessary to increase the punishment and apply criminal law if available. In short, the order of speech needs to be further improved under the We Media environment. The ultimate goal of criminal law intervention is not to restrict freedom of speech, but to ensure that freedom of speech is better realized.

\section{Acknowledgments}

This work was supported by the Youth Foundation Project of Wuhan Donghu University (No.2016028)

\section{References}

[1]Sangsuvan K. Balancing Freedom of Speech on the Internet Under International Law[J]. North Carolina Journal of International Law \& Commercial Regulation, 2014.

[2]Chen X, She J, Law S O. The Basic Position of Criminal Regulation on Internet Canard[J]. Journal of Jishou University, 2014, 596(5):106-112.

[3]Banks J. European Regulation of Cross-Border Hate Speech in Cyberspace: The Limits of 
Legislation[J]. European Journal of Crime Criminal Law \& Criminal Justice, 2011, 19(1):1146-8.

[4]Liu X. The Construction and Perfection of Criminal Law Regulation System about Online Rumors[J]. Jurist, 2016.

[5]Yi H E. Analysis Of Criminal Regulation On Cyber Crime of Defamation[J]. Journal of Fujian Police College, 2014.

[6]Chang S P. Online speech and democratic culture: a comparison of freedom of online speech between South Korea and the United States[J]. Asian Journal of Communication, 2016, 26(3):1-16.

[7]Yang B, Law S O, University G. Criminal Law Regulation of the Network Freedom of Speech in Network Era[J]. Journal of the Party School of Shengli Oilfield, 2017.

[8]Xiao C, Yuan J. On the Protection and Regulation of Citizens' Freedom of Speech on the Internet[J]. Journal of Beihua University, 2017.

[9]Huang B. Study on the criminal law regulation of We Media rumors from the perspective of "double-layer society"[J]. Journal of Liaoning Administrators College of Police \& Justice, 2017.

[10]Yang X. Study on the Legal Issues of Attorneys' Out-court Comments in Criminal Justice[J]. Tribune of Political Science \& Law, 2015.

[11]Singh S. Internet shaping freedom of expression; freedom shaping regulation[J]. Media Watch, 2017, 8(2):157-176.

[12]Yi-Rong M A, Yang L I, Law S O, et al. The Boundary of Freedom of Speech on the Internet and Libel[J]. Journal of Huaihua University, 2015. 